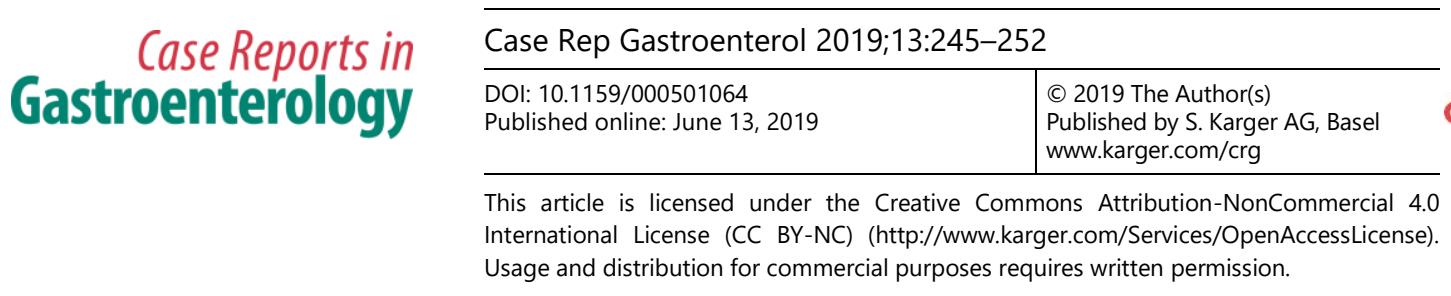

\title{
Inflammatory Pseudotumor of the Pancreas Mimicking a Pancreatic Neoplasm
}

\author{
José Miguel Baião ${ }^{a} \quad$ Rui Miguel Martins ${ }^{a}$ João Guardado Correia ${ }^{a}$ \\ Daniel Jordão ${ }^{a}$ Teresa Vieira Caroço ${ }^{a}$ Rui Caetano Oliveira ${ }^{b}$ \\ Paulo Gil Agostinhoc ${ }^{c}$ Henrique Ferrão ${ }^{a}$ \\ aSurgical Department, Instituto Português de Oncologia de Coimbra, Coimbra, Portugal; \\ bPathology Department, Centro de Diagnóstico Anatomo-Patológico (CEDAP), \\ Coimbra, Portugal; 'Radiology Department, Instituto Português de Oncologia de Coimbra, \\ Coimbra, Portugal
}

\section{Keywords}

Inflammatory pseudotumor - Pancreatic cancer - Pancreatectomy · IgG4-related disease . Myofibroblastic spindle cells

\begin{abstract}
A 78-year-old woman was admitted to our hospital with a pancreatic tumor, incidentally discovered in an abdominal ultrasound exam. She was asymptomatic and without any previous personal pathological condition. The computed tomography (CT) and the magnetic resonance imaging (MRI) scan showed a mass lesion of $4 \mathrm{~cm}$ in diameter, located in the pancreatic body, conditioning the invasion of the splenic vein. The patient was admitted to surgery. During the laparotomy, we found a tumoral lesion highly suspicious of pancreatic neoplasia located in the transition of the head/body of the pancreas, with an invasion of the portal vein and several peri-regional lymph nodes. We performed biopsies of the pancreatic mass and lymphadenectomy of the peri-regional pancreatic lymph nodes. Histological analysis found an inflammatory pseudotumor of the head/body of the pancreas, without signals of malign epithelial neoplasm and also without criteria for immunoglobulin G4-related disease. During the follow-up, a $\mathrm{PET} / \mathrm{CT}$ and MRI confirmed that the pancreatic lesion had disappeared without any treatment. Inflammatory pseudotumor of the pancreas is a rare entity not fully understood. Despite this,
\end{abstract}




\section{Case Reports in Gastroenterology}

Case Rep Gastroenterol 2019;13:245-252

DOI: $10.1159 / 000501064$

(c) 2019 The Author(s). Published by S. Karger AG, Basel www.karger.com/crg

Baião et al.: Inflammatory Pseudotumor of the Pancreas Mimicking a Pancreatic Neoplasm

the administration of corticosteroids and immunosuppressive therapy could be taken into consideration as the disease carries a risk.

\section{Introduction}

Almost $5-10 \%$ of pancreatectomies made with radiological suspicion of cancer have revealed nonneoplastic masses, also known as pseudotumors [1,2]. This entity is reported in the literature as a nonneoplastic space-occupying lesion that may occur almost everywhere in the body and has a varying course with various clinical presentations as well as multiple radiological and histological patterns [2,3]. Its etiology is mostly related to chronic inflammatory conditions, though it may also be the result of trauma, infectious diseases, congenital anomalies, and a lymphoproliferative process $[2,4]$.

Pseudotumors impose a diagnostic challenge as their differential diagnoses are wide. They resemble some conditions with a poor prognosis that can lead to procedures with a high level of morbidity. Herein, we report a case of inflammatory pseudotumor (IPT) of the head/body of the pancreas.

\section{Case Presentation}

A 78-year-old woman was referred to our hospital after being diagnosed with a pancreatic tumor in a routine abdominal ultrasound exam. The patient was asymptomatic and did not report losing weight nor any other complaints. Her previous medical history was unremarkable.

During the physical exam, the patient seemed well nourished, vital signs were within the normal range, and she was without masses in the abdominal exam. Routine blood laboratory results were within normal ranges. The referral ultrasound result reported a nodular hypoechogenic lesion with $4 \times 3 \times 3.3 \mathrm{~cm}$ in the pancreas tail, suspicious of an expansive process. An abdominal computed tomography (CT) revealed a globular shaped pancreatic body and a loss of cleavage plane between the splenic vein and the posterior face of the pancreas. For a better characterization, a pancreatic magnetic resonance imaging (MRI) was performed, showing a nodular lesion of the pancreatic body with $2.8 \times 2.5 \mathrm{~cm}$ causing pancreatic tail atrophy and distal dilation of Wirsung's duct (Fig. 1a). These findings were mostly compatible with a neoplastic lesion. A thoracic CT was performed and was negative for metastatic pulmonary lesions.

The patient's clinical case was discussed in a multidisciplinary meeting, and she was proposed for a surgical procedure with the diagnosis of pancreatic neoplasia clinically staged as T2 N0 M0 (Stage IB - AJCC 8th edition) [5].

She was submitted to a left subcostal laparotomy. During the procedure, a hard, bulky mass located in the transition of the pancreatic head/body was found. Intraoperative ultrasound showed close contact between the lesion and the portal vein (Fig. 1b), confirming local invasion after dissection. The performance of a tru-cut biopsy of the lesion and peri-regional lymphadenectomy (celiac trunk, interaortocaval, retropancreatic, and left renal artery lymph nodes) were decided on. There were no complications during or after the procedure, and the patient was discharged home on the ninth postoperative day.

Immunological and histological analysis found a dense and diffuse inflammatory infiltrate with mononuclear cells (Fig. 2a) as well as some plasmocytes and fibrosis (Fig. 2b). There was 


\section{Case Reports in Gastroenterology}

Case Rep Gastroenterol 2019;13:245-252

DOI: $10.1159 / 000501064$

c) 2019 The Author(s). Published by S. Karger AG, Basel www.karger.com/crg

Baião et al:: Inflammatory Pseudotumor of the Pancreas Mimicking a Pancreatic Neoplasm

positive marking for cytokeratins AE1/AE3 on a regular glandular pattern and highlighting of the lobulocentric pattern (Fig. 2c). Another cut showed dense plasmocyte (CD138 positive) infiltrates (Fig. 2d). Immunoglobulin (Ig)G4/IgG ratio was less than $40 \%$ of the plasmocytes. Positivity for CD34 was found only on vessels (Fig. 2e), excluding a solitary fibrous tumor. The expression for DOG-1 and CD34 was negative; also, anaplastic lymphoma kinase gene (ALK) marking was absent, excluding a myofibroblastic tumor (Fig. 2f).

The histological result was compatible with an inflammatory pseudotumor, without any signs of malign epithelial neoplasm, nor criteria for IgG4-related disease. The lymph nodes were also negative.

Two weeks after surgery, the patient was admitted to the emergency department complaining of vomiting and abdominal pain, exacerbated after meals. She underwent upper gastrointestinal endoscopy which showed a substantial gastric distention, with the stomach filled with stasis residue. Also, a marked decrement in peristalsis was noted, particularly on the gastric antrum. A barium-based contrast tract radiography was performed and confirmed the diagnosis of gastroparesis. A gastrojejunal anastomosis was performed and the patient fully recovered of the symptoms.

She was evaluated on a gastroenterology consultation, and postoperative PET/CT and MRI were scheduled. MRI showed an absence of the pancreatic mass, with a total resolution of pancreatic atrophy, and PET/CT also showed no sign of abdominal disease (Fig. 3). Her blood IgG4 levels were 405.7 (normal range values of 39.2-864.0). To date, the patient has been well and without any symptoms of the disease.

\section{Discussion}

Pancreatic cancer is an unwieldy diagnosis, being considered the seventh leading cause of cancer death in both genders worldwide, with 459,000 new cases reported in 2018 [6]. In European Union countries, it has been projected that pancreatic cancer will surpass breast cancer as the third leading cause of cancer death in the future [7]. Every patient diagnosed with a pancreatic mass shows a high level of concern about the exact nature of the lesion and, therefore, prompt guidance and medical evaluation towards a definitive diagnosis and treatment are fundamental.

"Inflammatory pseudotumor" is a term that is usually used to describe a quasi-neoplastic lesion that is composed of inflammatory cells and myofibroblastic spindle cells $[3,8]$. It is known to correspond to many different entities, with variable histological characteristics and behavior, even some with malignant behavior [8].

Its true origin remains unclear. Some authors argue that it is a result of an inflammatory process following minor trauma, surgery, and autoimmune mechanisms $[2,4,8]$. Some studies also point to a subset of pseudotumors that are secondary to bacterial and viral infection [3, 8].

Gastrointestinal tract involvement by this tumor type is rare, though they should be considered in the differential diagnosis of any abdominal and visceral mass. Ileocecal and gastric tumors are among the most frequently described sites for abdominal inflammatory pseudotumors $[3,8]$. Some of the most common presenting symptoms and clinical findings may include abdominal pain, a palpable mass, and iron deficiency anemia [3, 9].

Pancreatic malignant tumors are mostly from the epithelial origin, nonepithelial malignant tumors from mesenchymal origin being extremely rare, such as leiomyosarcomas, liposarcomas, neurogenic sarcomas, and malignant lymphomas [10]. IPTs may be distinguished 


\section{Case Reports in Gastroenterology}

Case Rep Gastroenterol 2019;13:245-252

DOI: $10.1159 / 000501064$

c) 2019 The Author(s). Published by S. Karger AG, Basel www.karger.com/crg

Baião et al:: Inflammatory Pseudotumor of the Pancreas Mimicking a Pancreatic Neoplasm

from lymphomas as they usually have a heterogeneous inflammatory cell population [8]. The distinction between spindle cell pattern tumors (malignant fibrous histiocytomas [MFH], inflammatory myofibroblastic tumor [IMP], and IPT) relies on histological and immunohistochemical analysis and is crucial to define the prognosis and proper treatment $[11,12]$. The IPT histological and immunochemical marking is different from MFH and IMP. The absence of p53 mutation and sole positivity for vimentin has been associated with MFH in recent reports; in IMP patterns, almost $50 \%$ of gene aberrations are reported, including ALK gene abnormality; and some reports present p53 mutation [10].

IgG4-related disease is known to present as a tumor-like swelling on affected organs. Type 1 IgG4-related disease represents a form of autoimmune pancreatitis, and patients often present with a subacute development mass, painless obstructive jaundice, and diffuse enlargement of the organ. These findings may be mistaken as pancreatic cancer [13]. Criteria for IgG4-related disease are a serum IgG4 concentration above $135 \mathrm{mg} / \mathrm{dL}$ and up to $40 \%$ of IgG+ plasma cells being IgG4+ (>10 cells/high-power field of biopsy sample). These criteria are helpful, but they are not sufficiently sensitive for the diagnosis of type 1 IgG4-related autoimmune pancreatitis [14].

The International Association of Pancreatology established an international consensus on the differential diagnosis of the 2 specific subtypes of autoimmune pancreatitis (types 1 and 2 ), which would be distinguished on the basis of 5 criteria: (1) imaging changes in the pancreatic parenchyma and duct; (2) serology (for IgG4 and IgG antinuclear antibodies); (3) extrapancreatic involvement; (4) histology; and (5) response to corticosteroid therapy [15]. In our presented case, only the first revised criterion was present, so we concluded that the IPT of the pancreas was not related to autoimmune pancreatitis (nor to IgG4-related disease).

Radiological study has an essential role in a most precise evaluation of these lesions, though the histological review is considered a necessary step towards a definitive diagnosis [3]. On CT studies, the appearance of these inflammatory tumors may be variable, from hypoattenuated to isoattenuated relative to the muscle and some calcifications may be present in liver, pancreas, or stomach pseudotumors. Some enhancement is seen on contrasted CT, but it is not pronounced and may have many different patterns of presentation [8]. MR images may also vary, and heterogeneous enhancement is reported after administration of contrast material, though this still cannot distinguish these lesions from a true pancreatic carcinoma [8].

As the definitive diagnosis of these lesions relies on their histological analysis, some of the specimens are acquired after surgical resection. As previously reported, 5-10\% of all pancreatectomies are made based on the imagological suspicion of cancer. It is considered that surgical resection of the mass is usually curative, though it may inflict morbidity to the patient and the possibility of surgical complications. Some reports point to the use of corticosteroid therapy, nonsteroidal anti-inflammatory drugs, and thalidomide to reduce the tumor volume $[3,9]$. The recurrence rate is estimated to be $18-40 \%$ [3]. These recurrent lesions may be locally invasive, and their resection may be recommended since a malignant transformation potential is still present [9]. Some reports of spontaneous regression have been noticed [3, 9].

IPTs represent a rare entity and are mostly an incidental finding in routine radiological exams or are discovered during the investigation of uncharacteristic symptoms or a detected mass from an unknown source. Their definite diagnosis relies on the association of radiological and histological evaluation, and each might be only available after surgical resection or biopsy. Surgical resection is the first line of treatment if the diagnose is not clear or was not previously done and it is curative in most cases. 
In our reported case, surgical resection was proposed at the start, but after the intraoperative findings and doubt about a possible vascular invasion, a more conservative approach was decided on to acquire material for the study and to decide on the results. As concluded from the results, a diagnosis of a benign lesion was achieved, and the lesion has fully remitted spontaneously, in agreement with some previous cases reported.

\section{Statement of Ethics}

Consent was obtained from the patient for publication of this case report and accompanying images. Ethical approval was not needed for this paper. Procedures and practice applied were according to leges artis.

\section{Disclosure Statement}

The authors state that they have no conflict of interest.

\section{Funding Sources}

This research did not receive any specific grant from funding agencies in the public, commercial, or not-for-profit sectors.

\section{Author Contributions}

José Miguel Baião: Study concept and design; data collection and analysis; writing the paper, review. Rui Miguel Martins: Data collection and analysis; writing the paper, review. João Guardado Correia: Data analysis, review. Daniel Jordão: Data analysis, review. Teresa Vieira Caroço: Data analysis, review. Rui Caetano Oliveira: Review. Paulo Gil Agostinho: Review. Henrique Ferrão: Review.

\section{References}

1 Lalwani N, Mannelli L, Ganeshan DM, Shanbhogue AK, Dighe MK, Tiwari HA, et al. Uncommon pancreatic tumors and pseudotumors. Abdom Imaging. 2015 Jan;40(1):167-80.

2 Adsay NV, Basturk 0, Klimstra DS, Klöppel G. Pancreatic pseudotumors: non-neoplastic solid lesions of the pancreas that clinically mimic pancreas cancer. Semin Diagn Pathol. 2004 Nov;21(4):260-7.

3 Patnana M, Sevrukov AB, Elsayes KM, Viswanathan C, Lubner M, Menias CO. Inflammatory pseudotumor: the great mimicker. AJR Am J Roentgenol. 2012 Mar;198(3):W217-27.

4 Sun MH, Tsai HM, Yu CY, Chen CY, Lin PW. "Mimics" of pancreatic carcinoma: pseudotumors of the pancreatic head. Zhonghua Fang She Xue Za Zhi. 2005;30:47-53.

5 American Joint Committee on Cancer. Exocrine Pancreas. In: American Joint Committee on Cancer, editor. AJCC Cancer Staging Manual. 8th ed. New York (NY): Springer; 2017. p. 337.

6 Bray F, Ferlay J, Soerjomataram I, Siegel RL, Torre LA, Jemal A. Global cancer statistics 2018: GLOBOCAN estimates of incidence and mortality worldwide for 36 cancers in 185 countries. CA Cancer J Clin. 2018 Nov;68(6):394-424.

7 Ferlay J, Partensky C, Bray F. More deaths from pancreatic cancer than breast cancer in the EU by 2017. Acta Oncol. 2016 Sep - Oct;55(9-10):1158-60. 


\begin{tabular}{l|l}
\hline Case Rep Gastroenterol 2019;13:245-252 \\
\hline DOI: 10.1159/000501064 & $\begin{array}{l}\text { @ 2019 The Author(s). Published by S. Karger AG, Basel } \\
\text { www.karger.com/crg }\end{array}$ \\
\hline
\end{tabular}

Baião et al.: Inflammatory Pseudotumor of the Pancreas Mimicking a Pancreatic Neoplasm

8 Narla LD, Newman B, Spottswood SS, Narla S, Kolli R. Inflammatory pseudotumor. Radiographics. 2003 MayJun;23(3):719-29.

9 Sanders BM, West KW, Gingalewski C, Engum S, Davis M, Grosfeld JL. Inflammatory pseudotumor of the alimentary tract: clinical and surgical experience. J Pediatr Surg. 2001 Jan;36(1):169-73.

10 Mizukami H, Yajima N, Wada R, Matsumoto K, Kojima M, Klöppel G, et al. Pancreatic malignant fibrous histiocytoma, inflammatory myofibroblastic tumor, and inflammatory pseudotumor related to autoimmune pancreatitis: characterization and differential diagnosis. Virchows Arch. 2006 May;448(5):552-60.

11 Lüttges J, Pierré E, Zamboni G, Weh G, Lietz H, Kussmann J, et al. [Malignant non-epithelial tumors of the pancreas]. Pathologe. 1997 May;18(3):233-7.

12 Zamboni G, Capelli P, Scarpa A, Bogina G, Pesci A, Brunello E, et al. Nonneoplastic mimickers of pancreatic neoplasms. Arch Pathol Lab Med. 2009 Mar;133(3):439-53.

13 Moutsopoulos HM, Fragoulis GF, Stone JH. Pathogenesis and clinical manifestations of IgG4-related disease. UpToDate. 2019. Available from: https://www.uptodate.com/contents/overview-of-igg4-related-disease

14 Umehara H, Okazaki K, Masaki Y, Kawano M, Yamamoto M, Saeki T, et al. Comprehensive diagnostic criteria for IgG4-related disease (IgG4-RD), 2011. Mod Rheumatol. 2012 Feb;22(1):21-30.

15 Okazaki K, Kawa S, Kamisawa T, Naruse S, Tanaka S, Nishimori I, et al.; Research Committee of Intractable Diseases of the Pancreas. Clinical diagnostic criteria of autoimmune pancreatitis: revised proposal. ] Gastroenterol. 2006 Jul;41(7):626-31.
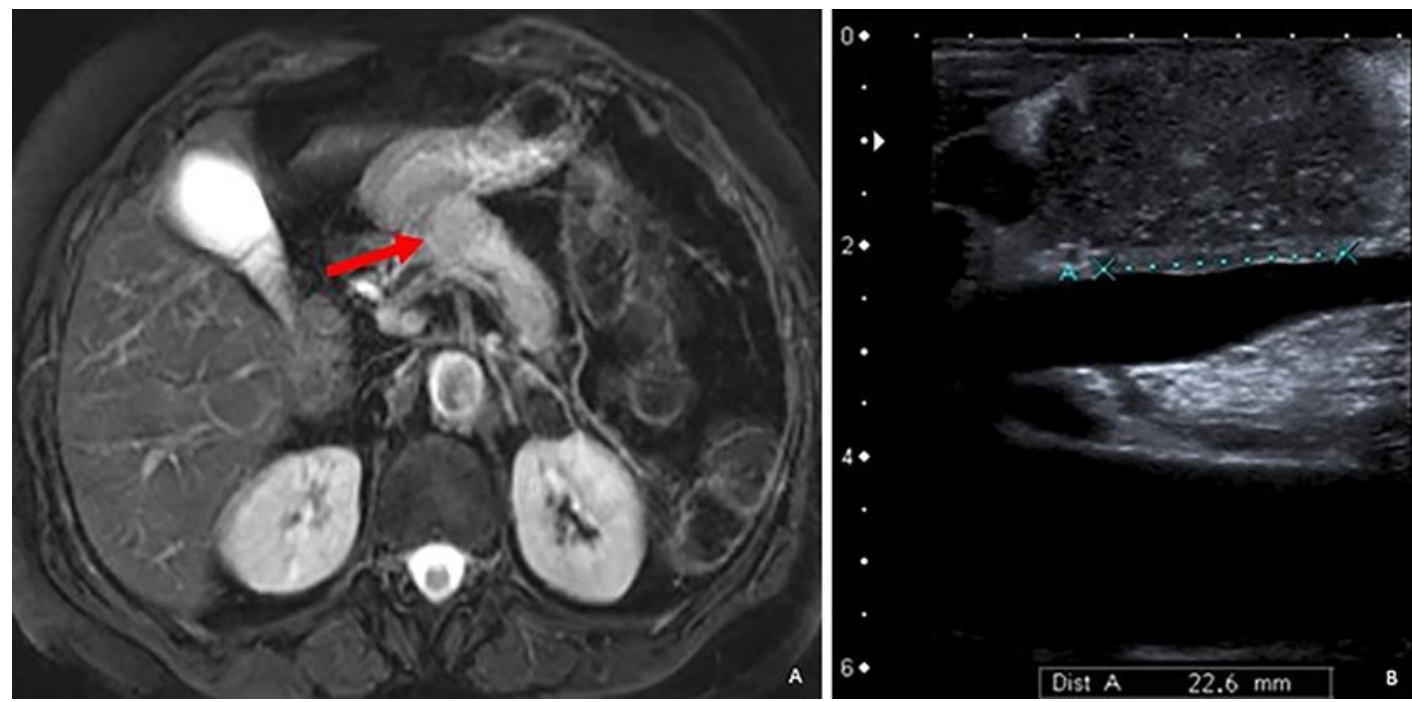

Fig. 1. a MRI (T2-weighted image) showing pancreatic mass (red arrow) and also tail atrophy and distal dilation of Wirsung's duct. $\mathbf{b}$ Intraoperative ultrasound showing a close contact between the lesion and the portal vein. 


\section{Case Reports in Gastroenterology}

\begin{tabular}{l|l}
\hline Case Rep Gastroenterol 2019;13:245-252 \\
\hline DOI: 10.1159/000501064 & $\begin{array}{l}\text { (c) 2019 The Author(s). Published by S. Karger AG, Basel } \\
\text { www.karger.com/crg }\end{array}$ \\
\hline
\end{tabular}

Baião et al.: Inflammatory Pseudotumor of the Pancreas Mimicking a Pancreatic Neoplasm
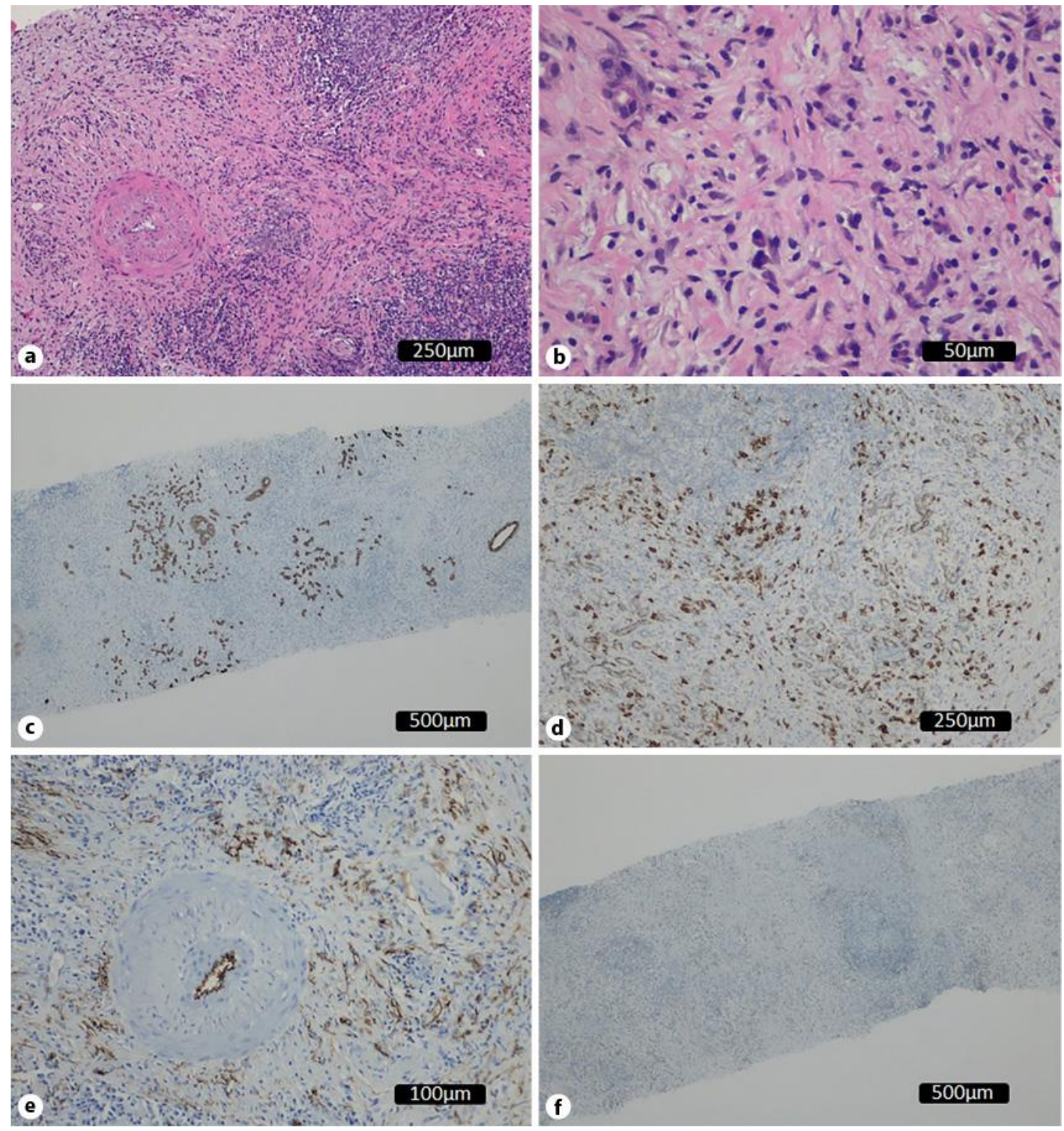

Fig. 2. Histological study. a Dense and diffuse inflammatory infiltrate with mononuclear cells $(\mathrm{HE}, \times 100)$. b Inflammatory infiltrate with plasmocytes and fibrosis $(\mathrm{HE}, \times 200)$. c Positivity for cytokeratins AE1/AE3: regular glandular pattern with lobulocentric pattern. $\mathbf{d}$ CD138 positivity marking - confirming plasmocytic infiltrate. e D34 positivity making on vessels. $f$ ALK-absent marking. 


\section{Case Reports in Gastroenterology}

www.karger.com/crg

Baião et al.: Inflammatory Pseudotumor of the Pancreas Mimicking a Pancreatic Neoplasm

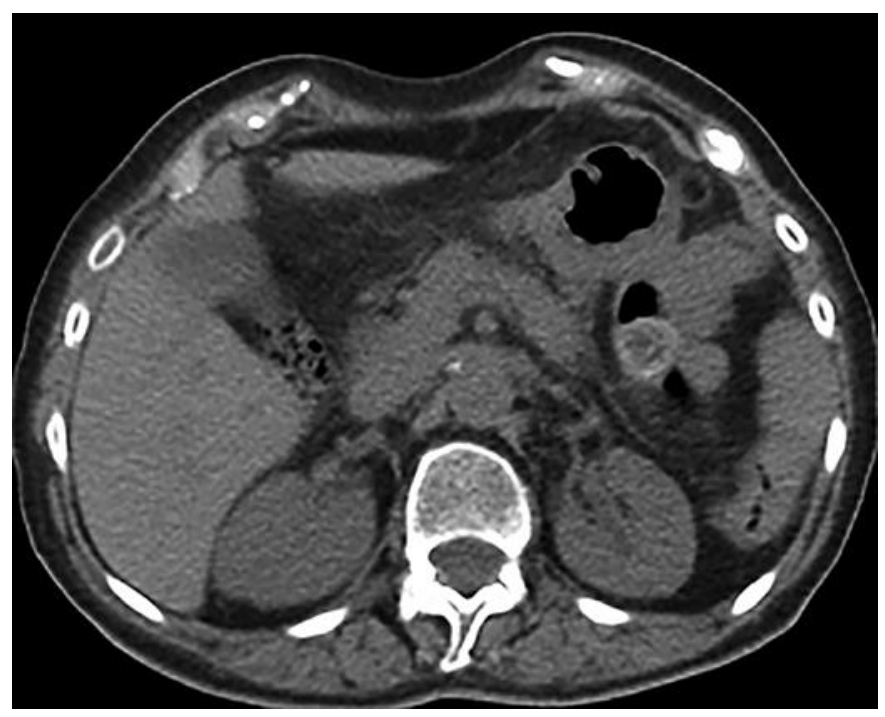

Fig. 3. CT scan showing no signs of the disease. 